1939

\title{
Congenital atresia of the bile ducts
}

Henry G. Crellin

University of Nebraska Medical Center

This manuscript is historical in nature and may not reflect current medical research and practice. Search PubMed for current research.

Follow this and additional works at: https://digitalcommons.unmc.edu/mdtheses

Part of the Medical Education Commons

\section{Recommended Citation}

Crellin, Henry G., "Congenital atresia of the bile ducts" (1939). MD Theses. 735.

https://digitalcommons.unmc.edu/mdtheses/735

This Thesis is brought to you for free and open access by the Special Collections at DigitalCommons@UNMC. It has been accepted for inclusion in MD Theses by an authorized administrator of DigitalCommons@UNMC. For more information, please contact digitalcommons@unmc.edu. 
CONGENITAL ATRESIA OF THE BILE DUCTS

BY

HENRY G. CRELLIN

\author{
SENIOR THESIS \\ UNIVERSITY OF NEBRASKA COLLEGE OF MEDICINE \\ APRIL 1939
}




\section{TABLE OF CONTENTS}

$\underline{\text { Page }}$

Definition _._._._-_._- 1

Hi story -

Normal Developmental Anatomy _.......... 2

Etiology

I Inflammation as a primary factor -...- 5

II Developmental anomalies as primary --Pathology

I General considerations _..._._._._. 8

II Nutritional changes _._._._._._._._- 10

III Changes in the liver _._._._._._._._._ II

IV Pathology of the gall bladder_-_._-_- 12

$\nabla \quad$ Pathology of the bile ducts -....... 12

VI Classification of deformities -...-.- 13

Symptoms

Diagnosis

I General diagnostic features _._._._._. 17

II Differential diagnosis _._._._._._._. 19

Prognosis _.

Treatment

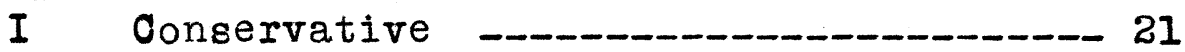

II Operative

A. Time of operation -_._._- 22

B. Technic - 22

III Cholangiography for determination of

Conclusions

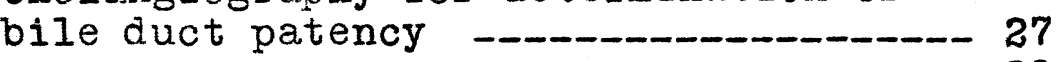

Case Reports

I Conclusions _._._._._. 44

Bibliography _-_._- 46

Acknowledgement _-_______- 49 


\section{DEFINITION}

Congenital atresta of the extra hepatic bile ducts is a rare developmental abnormality resulting in an absence or stenosis of all or any portion of the biliary ductal system.

\section{HISTORY}

Icterus Neonatorum was recognized for many years before it was appreciated that a certain small percentage of these cases were associated with malformations of the biliary tract. Isolated examples were reported of Icterus developing at birth or shortly afterwards which were found at autopsy to be due to atresia or complete absence of the extra bile ducts.

The first comprehensive study of this condition was made by Thomson in 1892. His report was based on a critical analysis of fifty nine cases collected from the literature.

In 1901 Rolleston and Hayne (24) reported nine cases and advanced the theory that the condition was due to a fetal intoxication which first produced a biliary cirrhosis, followed by a secondary closure of the larger radicles of the biliary duct system. Lavenson (17) in 1908 abstracted a total of sixty two cases and in 1911 Howard and Wolbach (II) added seventeen more. By 1937 a total of more than two hundred cases had been 
reported in the literature. Numerous and varied were the etiological concepts but it is now generally concluded that the condition is due to a secondary occlusion of the bile ducts, a.e., a developmental arrest occurring early in embryological development.

The condition was generally regarded as having a hopeless prognosis and that attempt at surgical correction of the deformity was a futile, but well meant gesture. In the ten year period from 1928 to 1938 Ladd (15), Donovan (6), and others working independently, reported nine cures by surgery out of a group of twenty five cases which were treated surgically.

\section{NORMAL DEVELOPMENTAL ANATOMY}

A clear concept of congenital atresia of the bile ducts is predicated on an accurate understanding of the embryological development of the liver and its radicles.

The development of the biliary system is complex and all phases of it are not clearly understood. The liver first makes its appearance in the $3 \mathrm{~mm}$. embryo as a longitudinal evagination from the ventral surface of the gut in the duodenal area. As development continues, the evagination forms a cephalic portion, the Pars Hepatica, which is the anlage of the liver, and a 
caudal portion, the pars cystica. This latter portion, the forerunner of the gall bladder and the biliary duct system, is hollow at first and is connected wi th the lumen of the gut. This evagination elongates and constricts from the gut until only a narrow cord of cells connects the biliary anlage to the intestine in the $8 \mathrm{~mm}$. embryo. Differentiation of the duct system begins at the $6 \mathrm{~mm}$. stage of development. The pars hepatica grows rapidly and is attached to the common duct anlage by a short cord of cells which will become the hepatic duct. The pars cystica, which also grows rapidly, is connected with the common duct by a short cord of cells which is the anlage of the cystic duct. The pars cystica grows into the ventral mesentery and thus becomes surrounded by mesodermal tissue. Its proximal portion continues to elongate, forming the cystic duct, and the distal portion dilates and enlarges to form the gall bladder.

The pars hepatica also grows into the ventral mesentery and becomes surrounded by mesodermal tissue, which is the anlage to the fibrous capsule of Glisson of the liver,

The vascular supply of the developing liver is first by sinusoidal blood veșsels which aid in the 
division of the liver into lobules and trabeculae.

Consideration should be given to the size, length and lumen of the developing ducts, as the most logical etiological suppositions are based on them. In the $6.7 \mathrm{~mm}$. embryo the gall bladder and common ducts are solid. At $7.5 \mathrm{~mm}$. the gall bladder remains solid, and a lumen forms in the common duct which is subdivided near the hepatic duct. In the $10 \mathrm{~mm}$. embryo the gall bladder and extra hepatic ducts are larger and more slender. The gall bladder, cystic and common ducts cavitate at this stage but at $15 \mathrm{~mm}$. they again become solid due to epithelial proliferation.

The pertinent facts regarding duct development are well summarized by Ladd (15) who states that bile duct development is analagous to that of the intestine, as the lumen of both become obliterated by epithelial proliferation. If normal development continues the solid cords vacoulate, these then coalesce, and the lumen is established. Arrest of development in the solid stage explains malformations better than other theories, which will be considered later. The cause of such arrests are unknown. 


\section{ETIOLOGY}

The exact etiology of congenital atresia of the bile ducts is unknown, and consequently, as in all phases of scientific investigation, this obscurity leads to a multiplicity of theories varying widely in the ir rationale.

Two major concepts have been presented. First, that extra hepatic ductal obstruction is secondary to a toxic or infectious hepatic cirrhosis; second, that duct involvement is primery and the cirrhosis is secondary. Many explanations are given for the occurrence of both the duct atresia and cirrhosis.

I Inflammation as a primary factor.

Rolleston (24) believed that maternal toxins in the fetus first produced a descending cholangitis which eventually resulted in the obliteration of first, the intra hepatic ducts and then the larger branches. His reasons for this conclusion were: that complete obstruction in adults does not result in cirrhosis, and that splenomegaly often seen in congenital atresia of the bile ducts does not occur in simple obstruction. His conclusions were based almost entirely from observations made at autopsy on one case. 
Wyard (28) later advances the view that obstruction is due to an ascending cholangitis caused by circulating blood toxins, but readily admits his inability to account for the origin of the latter.

Holmes (10) disposes of the notion of congenital lues as being an etiological factor by finding negative Wassermann's in his series of cases.

He believed that catarrhal processes produced narrowing of the ducts, giving rise to stasis, increased inflammation, blockage, and finally obliteration, usually early in intra uterine life. He also believed that the peritonitis often seen in fatal cases at autopsy was always secondary to the malformations present. Holmes also gives some stock to the idea that the obstruction might be due to adhesions forming as a result of fetal peritonitis, and after birth, infection from intestinal organisms might complete the obliteration process.

II Developmental anomalies as primary factors

Earsons (22) presents a case, summarizes the literature and concludes that both a developmental aplasia and a cholangitis occur concurrently in 
congenital atresia but readily admits that his case showed only a biliary cirrhosis and no cholangitis.

Lavenson (17) whose article and conclusions were based on observation of a number of cases advanced the idea that cirrhosis was secondary to duct obstruction, as all early deaths due to this anomaly showed little cirrhosis, that there was no duct obstruction in adult biliary cirrhosis, and that most obstructions are seen in the duodenal end of the common duct.

Kixshbaum (13) believes that congenital atresia of the bile ducts is a primary developmental disturbance manifested by a complete or partial absence of the bile ducts. He also introduces the idea of a mechanical factor, a.e., a large liver, by exerting traction on mesenteric bands results in a twisting or blocking of the ducts, usually near the ampula of Vater. This is not logical as the cause of the large liver is unexplained and obstruction elsewhere in the duct system than in the distal end of the common duct is not accounted for.

The theory is also mentioned in which the cause of the obstruction is believed to be due to 
an ingrowth of duodenal epithelium at the level of the papilla of Vater. The supporting evidence is lacking. It is also thought that anomalies of the fetal vitelline and umbilical vessels may result in anomalies of the biliary passages.

\section{PATHOLOGY}

\section{General Considerations}

The general pathological picture in all cases is quite uniform. All pathological disturbances are the result of obstruction to the outflow of bile from the Iiver.

A generalized icterus is manifest in every case. A week's'delay in its appearance, which is sometimes seen, might seem to indicate that the extra hepatic ducts were patent at birth. Watkins and Wright (27), however, disagree with this explaination. They state that bile pigment is not secreted until the sixth month of fetal life and then only in small amounts until birth. The delayed onset of the jaundice coincides with the increased production of bile following birth and consequently does not necessarily mean post natal closure of the biliary tract. Howard and Wolbach (II) observe that adhesions and ascites are uncommon findings in congenital atresia of the bile ducts. 
Splenic enlargement is seen in about seventy five percent of the cases. Rosenberg and Judd (23) affirm this to be due to an increase in size and number of endothelial cells lining the venous loops and splenic sinuses and suggests an attempt on the part of the spleen to assume the phagocytic function of the damaged liver cells.

Montgomery (20) adds secondary anemia, cholemia, and gradual increasing emaciation to the list of secondary pathological manifestations.

Rolleston (24) believes that maternal toxins passing to the fetus first cause a portal or multilobular cirrhosis of the liver, inducing the formation of another toxin which is introduced into the intra hepatic ducts, setting up cholangitis and a monolobular cirrhosis, wich in turn induces a mixed portal and biliary cirrhosis. Cholangitis then descends to the larger ducts, giving rise to an obliterating cholangitis. As proof for his unique concept he states that early in development the ducts are small so consequently a disease process does not have to be marked to produce the observed pathological changes as he describes them. Other reasons he gives are that cirrhosis with complete obstruction does not accur in the adult, that in adults atrophic cirrhosis accompanies obstruction, that 
splenomegaly is not seen in simple obstruction in adults, and that the condition is a familial tendency. Later case studies have proven the latter statement to. be incorrect.

Cole (3) attributes all deaths in congenital atresia of the bile ducts to be secondarily due to otitis media, pyelitis, acute bronchitis, and pneumonia.

\section{Nutritional Changes}

Altshule (I) studied eleven cases of congenital atresia of the bile ducts from the standpoint of fat metabolism and vitamin deficiency. He found marked vitamin A deficiencies in six of these cases notwithstanding the fact that they were fed on a diet rich in this vitamin. Evidence of vitamin A deficiency is atrophy of the epithelium of various organs and replacement with stratified keratinizing epithelium, rising close to the basement membrane. It is first evident in the trachea, renal pelvis, and lastly on the cornea of the eye. It is concluded that the faulty vitamin $A$ absorption is directly due to absence of bile in the intestine.

Parsons and Herkman (22) observed that the unabsorbed fat in the gut, due to an absence of bile, resulted in a negative calcium balance associated with 
a low blood phosphorus, but that there was no change in the rate at which nitrogen was absorbed. Holmes (10) states that fat assimilation is reduced to about forty percent, the normal being about ninety percent. Lipolytic ferments which are present if the pancreatic duct is patent cannot function properly in the absence of bile salts.

\section{Changes in the Liver}

\section{A. Gross}

Changes reported by the various contributors are quite uniform. The liver presents the picture of bile stasis and biliary cirrhosis, a.e., it is a dark green color, shows varying degrees of enlargement, is firm to the touch and has a hard irregular pebbly surface. Howard and Wolbach (II) state that the cirrhosis seen in their cases is an advanced type, is mixed, but is mostly biliary in location. They also observe that the portal vein is normal. Confirming these findings, Laboe (14) states that the pathology is seen only in the larger, more distal bile radicles.

In opposition to the views of most of the contributors, Montgomery (20) claims to have found portal cirrhosis and atresia of the intra hepatic ducts, sometimes extending to the finer bile capillaries. 


\section{B. Microscopic}

The main observations microscopically are various degrees of replacement of normal tissue with fibrous tissue.

Ladd (16) finds marked interlobular and intralobar fibrosis with slight round cell infiltration in some cases. The bile capillaries are plugged with greenish-black inspissated bile. The liver cells contain small granules of bile pigment. Particles of pigment are also found in phagocytic cells of the small capillaries in the interstitial fibrous tissue.

\section{Pathology of the Gall Bladder}

Absence, fibrosis, or obstruction of the gall bladder is a common accompaniment of the varied anomalies of the bile ducts, and plays an important role in the treatment of this condition. When seen alone, without hepatic or common duct obstruction, it results in no impairment of health and is rarely accompanied by dilitation of the hepatic or common ducts.

\section{Pathology of the Bile Ducts}

Donovan (6) makes the statement that any portion of the bile ducts may be absent and the gall bladder may be absent, present or atrophied. Obliteration of the ducts may be found anywhere, but most often in 
the common duct area.

Holmes (10) adds that minor abnormalities, especially those affecting the cystic duct occur quite frequently. Common and cystic duct atresias occur with about equal frequency. Fifty percent of the lesions of the common duct are accompanied by impervious cystic ducts or malformations of the hepatic ducts. In sixteen percent of all atresias, the cystic and hepatic ducts are normal and communicate with each other. Upon reviewing all the available cases in the literature I found that in one hundred thirteen of these the data regarding duct defects as found on operation or necropsy or both was sufficient to warrant a comparison. Of these cases I found that in twenty six percent the hepatic and cystic ducts and gall bladder were patent and communicated with each other. This is somewhat higher than Holmes figures, compiled from the cases reported prior to 1915 .

VI Classification of Deformities

Almost every possible combination of duct deformity has been observed, and in no two cases are the anomalies exactly alike in every respect. Most of the observed deformities, however, will fit into the following classification: 
1. Absent extra hepatic ducts.

2. Atresia of hepatic ducts.

3. Atresia of common duct.

4. Atresia of hepatic and common ducts with patent gall bladder and cystic duct,

5. Atresia of gall bladder and cystic duct with patent common and hepatic ducts.

6. Atresia of cystic and hepatic ducts are the most common.

7. Atresia of intra hepatic ducts with patent gall bladder and extra hepatic ducts.

8. Gall bladder directly connected with duodenum but absence of extra hepatic ducts.

9. Narrowing of common duct causing partial obstruction.

10. Stenosis of common duct plugged with inspissated bile, causing complete obstruction.

\section{SYMPTOMS}

I Jaundice is present in all cases of congenital atresia of the bile ducts and usually appears during the first three weeks of life. Croswell (4) believes that jaundice appearing after the first month indicates that the atresia was probably not complete at birth. Holmes 
(10) states that the usuall three to five day delay in the appearance of the jaundice may be due to the fact that the liver produces but little bile pigment until the time of birth and that the liver normally has a capacity for storing a certain amount of bile pigment, and as a result the jaundice does not appear until the threshold of this function is reached.

The jaundice progresses steadily throughout the course of the disease until the entire body surface is a greenish-yellow color. Howard and Wolbach (II) add that the character of the jaundice may show a slight daily variation and that it may become paler just preceeding death.

\section{Hemorrhagic Tendencies}

Such changes as petechial hemorrhages into the skin and mucous membranes, apparently spontaneous bleeding from the nose, umbilicus conjunctiva, stomach or intestines, occur in about fifty percent of the cases a few weeks after birth. Profuse hemorrhage very often follows trivial puncture wounds or circumcision.

Howard and Wolbach (II) attribute this predisposition to hemorrhage to three factors, namely: a decrease of the red blood cell-fibrin ratio, hemolysis of the red blood cells by biliary acids in the blood, 
and a parenchymatous degeneration of the blood vessel walls by bile acids.

\section{Acholic Stools}

Complete absence of bile in the stools is usually present at birth. Slight color of the stools in the presence of complete obstruction may be due to bile stained intestinal mucus, intestinal bacterial action, or mercury medication.

IV Meconium

Jaundice which appears early in the fetus usually results in a yellow colored meconium. $\checkmark \quad$ Biliuria

Bile is always present in the urine. The urine is just slightly changed or it may be so concentrated that it assumes a dark bronze color. VI Liver Enlargement

The resulting cirrhosis produces a definite hepatomegaly. During the first month of life there is a progressive enlargement of the liver but as the atrophic type of cirrhosis appears the rapidity of growth is retarded.

VII Splenic Enlargement

Passice congestion or an increase in the size and number of endothelial cells lining the venous loops 
and splenic sinuses causes splenic enlargement and suggests an attempt of the spleen to assume the phagocytic function of the damaged liver cells. It occurs in about seventy five percent of the cases and is usually noticed after the first month of life. VIII Emaciation

The appetite and general nutrition of the affected infants are usually good until the third month or until a secondary infection sets in. The appetite decreases and emaciation usually progresses rapidly after the third or fourth month.

IX Vomiting

Vomiting is observed in only about ten percent of the cases and tends to become more marked at the terminal stages.

\section{DIAGNOSIS}

I General Diagnostic Features

According to Ladd (16) arriving at a correct

diagnosis within the first two or three weeks is difficult but the chances of error are not great if the diagnosis is deferred until the fourth or sixth week of life. 
Jaundice may be present a few days after birth, but becomes more marked after two or three weeks. By the second month the skin has a definite greenish yellow hue and at the third month a pasty green color.

The stools are usually acholic but sometimes give a weak positive test for bile or show bilestained mucus on their surface.

The urine is dark colored and is positive for bile.

The icterus index is a valuable diagnostic feature. It shows a daily variation from fifty to two hundred, the normal being three to five.

Bleeding and clotting time may be slightly prolonged, but no marked variation from normal has been consistantly noted.

The fragility of the red blood cells is normal and the erythroblasts are not much increased. The number of red blood cells and the percentage of hemoglobin are below normal in some cases, especially in the terminal phases of the disease.

The Van der Bergh reaction shows a direct positive and is not biphasic.

On physical examination the patients show a good state of nutrition and development even when several 
months old. The icterus is marked and the liver is much enlarged with a firm and hard edge.

\section{Differential Diagnosis}

A. Icterus Neonatorum This condition is present in thirty to eighty percent of all newborn children. The jaundice usually appears on the third day, increases in intensity for two days, and then gradually disappears. If severe, the jaundice may be marked for two weeks at the most. In icterus neonatorum there is no enlargement of the liver and bile is present in the stools.

\section{B. Syphilitic Hepatitis This is excluded} by negative serology findings in the child and its parents, and by characteristic changes in the iong bones which are easily recognized by roentgenograms. Jaundice is rarely seen in syphilitic infants and when present it is usually not marked.

\section{c. Oongenital Hemolytic Icterus Donovan}

(5) states that this disease is rare in young children

and is always accompanied by increased fragility of the red blood cells.

D. Septic Jaundice This usually continues for more than two weeks and greatly increases in severity. It is usually due to umbilical infection 
of which hemorrhage from the cord stump is a prominent feature. Jaundice does not progressively increase, there is no biliuria, no high icterus index, there is a varying elevation of temperature, and a positive blood culture is usually found.

E. Tuberculous Lymphadenitis of the nodes surrounding the bile ducts may cause obstructive jaundice by pressure directly on the ducts. It occurs in older children and is a rare finding.

F. Obliteration of the Ampule of Vater This can be ruled out by finding both bile and pancreatic enzymes absent upon passing a duodenal catheter.

G. Erythroblastosis, Icterus Gravis, is diagnosed by an increased number of erythroblasts in the blood and a biphasic Van der Bergh reaction. This disease hasahigh mortality within the first few days of life.

\section{PROGNOSIS}

In untreated cases of congenital atresia of the bile ducts the outcome is invariably fatal as complete obstruction of bile outflow is incompatable with Iife.

The prognosis of treated cases has changed much 
in the past two decades. This has been due largely to greater efficiency in the early diagnosis of the condition and to improved surgical technique.

Holmes (10) in 1915 gathered more than one hundred cases from the literature and concluded that in sixteen percent of them the anatomical defects could be corrected by surgery. He also believes, however, that even though the existing abnormalities could be corrected, the resulting hepatitis and cirrhosis generally proved fatal.

A survey of all the cases reported to date shows that surgical establishment of bile drainage was possible in twenty six percent of the cases.

Ladd (15), who seems somewhat over optimistic, states that thirty seven percent of his cases were possible cures and that sixty percent of this group were cured. He firmly believes that the liver has sufficient regenerative power to overcome the cirrhosis after adequate bile drainage is established.

\section{TREATMENT}

\section{Conservative}

From a curative standpoint, Howard and Wolbach

(11) correctly state that medical treatment of congenital atresia of the bile ducts is utterly valueless. 
Altschule (1) and Croswell (4) suggest that oral administration of a mild intestinal antiseptic, bile salts, and massive does of vitamin A, along with a low fat diet, might be of some value.

\section{Operative}

\section{A. Time of Operation All investigators}

are agreed that the most opportune time for surgical treatment is between the first and second months of 11fe. It is inadvisable to operate before the end of the first month, as a positive diagnosis can seldom be made before this time. If the procedure is delayed beyond the second month the outcome is much poorer due to the general lowering of resistance because of emaciation, the increased tendency to hemorrhage, and the lowered resistance to infection.

\section{B. Technique of Operation Obviously, an} exploratory celiotomy should be done in all cases. Holmes (10) believes that establishment of bile flow is possible only when the common duct is obstructed, and the gall bladder, eystic and hepatic ducts are patent. He adds that the hepatic duct is so small that anastamosis between it and the duodenum cannot be made. Ladd, however, has reported cures from duodenal common duct anastamosis. 


\section{Diagnosis of Type of Deformity}

Ladd (15) states that diagnosis of the deformity is usually made difficult by the small size or obliteration of the ducts, or by the presence of folds of peritoneum from the colon or duodenum.

One or all of the following procedures should be tried until the type of deformity is definitely ascertained:

1. Attemit should be made to dissect out the course of the ducts.

2. If the common duct is hard to find insert a catheter into the gall bladder and inject normal saline solution, and if patent, the cystic and common ducts will be distended down to the obstruction. If the obstruction is due to stenosis of the common duct by a bile or mucus plug it may be dislodged.

3. Attempt should be made to pass a probe through to the duodenum.

4. When the cystic duct and gall bladder are present but atrophied, the latter may be freed from its bed and used to pull the common and hepatic ducts into view. 
5. Injection of a radio-opaque substance into the gall bladder or common duct can be done on the operating table and accurate roentgenographic outlines of existing abnormalities can be visualized.

2. Treatment of Intra Hepatic Duct Obstruction

Obstruction inside the liver substance is most often in the right or left hepatic ducts. It can be definitely determined at operation only by a cholangiogram. If obstruction is due to stenosis by inspissated bile, this may be dislodged by irrigating the ducts with normal saline. If obstruction is due to atresia nothing can be done.

3. Treatment of Hepatic Duct Obstruction

This condition is best diagnosed also by a cholanglogram. Attempt should be made to dislodge a possible mucus or bile plug by injection of normal saline into the duct system. If adhesions are compressing or impinging on the hepatic ducts these should be divided. No instances of successful treatment of hepatic duct obstruction are on record. 
4. Treatment of Common Duct Obstruction

The object of treatment is to establish

bile drainage into the duodenum.

Donovan (6) suggests that cholecystogastrostomy and cholecystoduodenostomy are satisfactory methods if enough tissue is present to perform the anastamosis. Most of the recorded surgical cures have been subjected to this type of treatment.

Drainage to the outside may be established, and the fistula which is produced is later Implanted on the stomach or duodenum. This procedure involves a great risk of infection at the time of the second operation, and no evidence of its successfuly use has been found in the literature.

Saline may be injected into the duct system at operation which may remedy the obstruction if it is due to a mucus plug. Some cures are on record by the use of this treatment alone.

Ladd (16) believes that the anastomosis of the gall bladder to the stomach is not the best procedure unless the patient's condition will not warrant the use of any other method. 
Most contributors are of the opinion that any portion of the common duct is too small for anastomosis to the duodenum. However, Ladd (15) reports one cure in which he used this method. The technic of this procedure as he describes it is as follows: A small catheter is inserted through the gall bladder, cystic duct, and into the common duct. The blind end of the duct is then attached to the duodenum and openings are made in both, through which the catheter was passed. The anastamosis is then completed and the catheter is withdrawn. The anastamosis of the common duct with the duodenum over a short length of catheter may be done, allowing the tube to be carried on down the gastro-intestinal tract. Some common errors in operative procedure are: Mistaking fluid in the gall bladder for bile and doing an anastamosis when the gall bladder is not connected with the liver. Cholecystoenterostomy may be done in the absence of extra hepatic ducts. The gall bladder may be connected with the duodenum but the hepatic ducts are absent. This error can be eliminated by the use of a cholangiogram. If too long a, tube is used in making the required anastamosis it may fail to 
pass on down the intestine and ulcerates through the bile duct, causing peritonitis.

\section{Oholangiography for Determination of Bile Duct}

\section{Patency}

This method for a more exact determination of bile duct patency in cases of congenital atresia of the bile ducts at operation was originated and first used by Dr. N. Frederick Hicken, Omaha, in 1938. At that time the chief methods of locating biliary duct obstructions consisted of palpation of the ducts in an effort to locate sones, injecting salt solution into either the gall bladder and determining the presence of a possible atresia, stone or stenosis by duct dilitation directly above the point of obstruction, and probing of the cystic and common ducts. In congenital atresia of the bile ducts these methods of diagnosis of the location of the obstruction at operation were often inadequate, as evidenced by the number of errors recorded among the cases which were treated surgically.

The procedure consists of injection of a radio-opaque fluid, Skiodan Vicious (Winthrop), into the gall bladder. If the latter is not patent the fluid is injected into the common duct. A cholangiogram is then taken at the operating table and its 
interpretation will govern operability and the type of operative anastamosis to be used.

In addition to the cholangiogram, photographs of the baby and of the liver and bile ducts should be routinely taken.

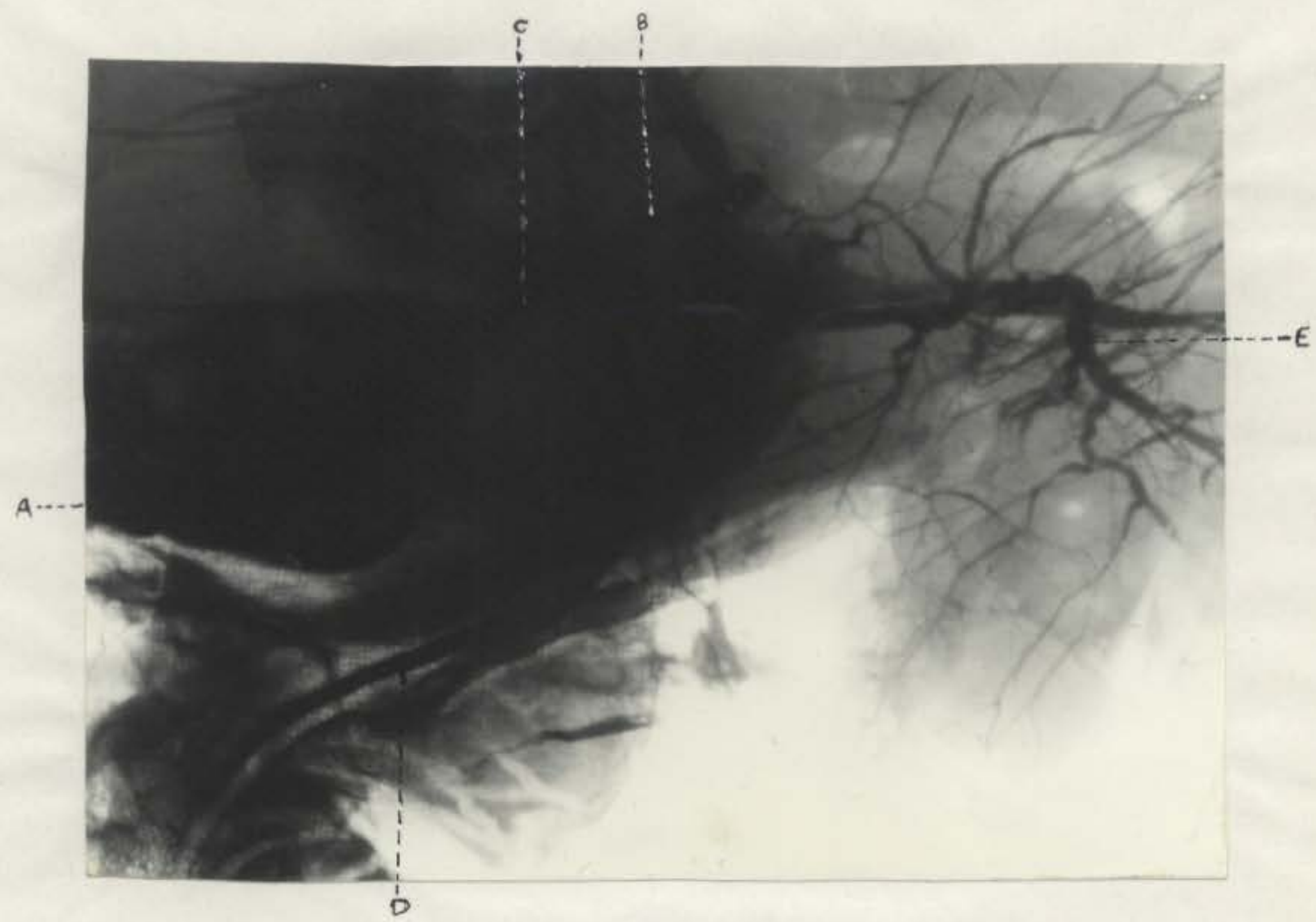

Cholangiogram of a normal biliary ductal system Skiodan injected into gall bladder of infant at autopsy. A - Gall bladder; B - Hepatic duct; C - Cystic duct; D - Common duct; E - Intra Hepatic ducts 


\section{CONCLUSIONS}

1. The obstruction occurring in congenital atresia of the bile ducts is most likely due to the failure of any portion or all of the extra hepatic duct system to recanalize. This occurs early in embryological development.

2. Duct defects may be complete or'partial absence or atresia of any portion of the extra hepatic ducts. Twenty six percent of the defects are anatomically ammenable to surgical treatment. Cirrhosis increases progressively as the child becomes older, is secondary to the obstruction of bile outflow, and is chiefly biliary in type.

3. Diagnosis of congenital atresia of the bile ducts between the fourth and sixth week of life is easily made and is imperative as the child tolerates surgery badly after this condition has progressed beyond the second month.

4. In addition to the usual preoperative treatment, the use of a fat-free diet, vitamin A concentrates and bile salts is valuable.

5. The injection of a radio-opaque substance into the gall bladder or common duct and the taking of an $x$-ray picture at operation is the most accurate method of 
diagnosis of the extent and location of the duct obstruction. This method if used greatly lessens the surgical insult which the infant is subjected to.

\section{CASE REPORTS}

The following five cases have been seen by Omaha physicians in the past three years and have not, as yet, been reported in the literature.

\section{Case I}

P. P., a white male child, was first seen by Dr. J. A. Henske when it was three months old. At this time the child showed a marked generalized jaundice, acholic stools, biliuria, enlarged liver, and was diagnosed as congenital atresia of the bile ducts.

The child's mother was apparently normal throughout pregnancy. The labor was normal, the birth weight was nine pounds, four ounces, and a slight jaundice was noticed at birth. On the fourteenth day the child began to bleed from the umbilicus, bowel, and mouth. It was taken to a neighboring city and was treated by being given a blood transfusion and fibrinogen. The bleeding ceased following this treatment and although it was noted at this time that the child had acholic 
stools, no diagnosis was made. At the age of three months the child was brought to Dr. Henske who made the diagnosis and informed the parents that the prognosis was hopeless. The child was then taken home and died at the age of four months, seventeen days.

An autopsy performed by Dr. Starrey of Sioux City, confirmed the diagnosis. A markedly enlarged greenish-yellow hob-nailed liver, showing marked cirrhosis was found. The gall bladder was the size of a pea and the common, hepatic and cystic ducts were represented as small fibrous cords.

\section{Oase II}

L. C., a white female child, was apparently normal at birth and had a normal delivery. The weight at birth was seven pounds, eight ounces.

On the third day jaundice appeared. This progressively increased and the child failed to gain weight. At the age of six weeks the child was taken to Dr. J. A. Henske who found no weight gain since birth, an absence of bile in the stools, marked generalized jaundice, bronze colored urine, and a markedly enlarged liver, the lower border of which was felt at the crest of the ilium. It was also noted 
that the child had an umbilical hernia.

At this time the child was placed on a fat free diet and Bilron, (a bile salt preparation) one third of a capsule, T.I.D. The child improved on this regime and on the third month the weight had increased to ten pounds, nine ounces.

The the fourth month the child's weight was twelve pounds, four ounces, the liver was much smaller and ascites had developed. Paracentesis was done on the fifth month twice each following week to relieve the distention and about 600 cc of fluid was removed each time.

Emaciation rapidly developed and the child died at the age of five months, fourteen days.

The autopsy was performed by Dr. C. P. Baker, Omaha. The body showed pitting edema of the lower extremeties, a moderate degree of emaciation, and a severe generalized jaundice.

The abdomen was markedly distended and contained approximately three hundred cc of bile tinged fluid. The liver was down three centimeters in the mid clavicular line. A small umbilical hernia sac was also found.

The right middle lobe of the lung showed 
congestion and consolidation, the right lower lobe was a.lso consolidated, and the left lower lobe consolidation was indicative of terminal bronchial pneumonia.

The thymus was present and weighed one gram. The enlarged spleen weighed 150 grams (four times the normal) was firm, had a normal color and showed a moderate amount of congestion.

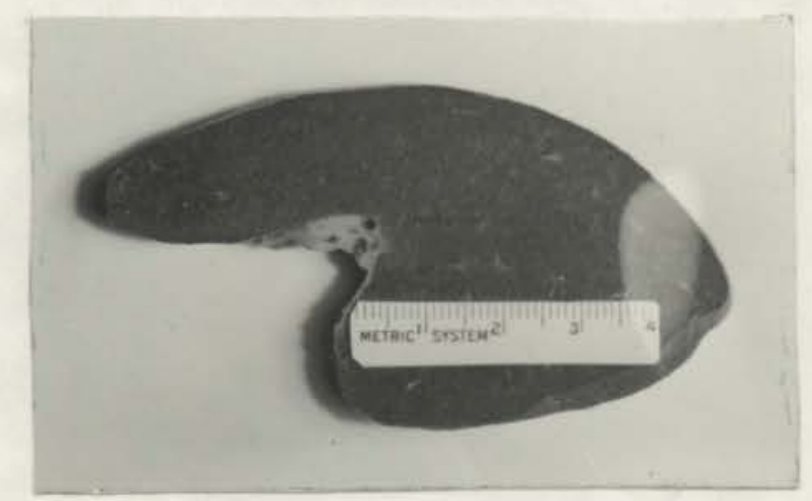

Case L. C. Cut surface of liver showing intrahepatic duct dilitation and cirrhosis.

The liver weighed 400 grams, three times the normal. The surface was a greenish-yellow color, and was covered with many finely granular nodules. The substance was firm and the out surface also showed the greenish-yellow color. The markings are indistinct but the intra hepatic bile ducts are dilated. 


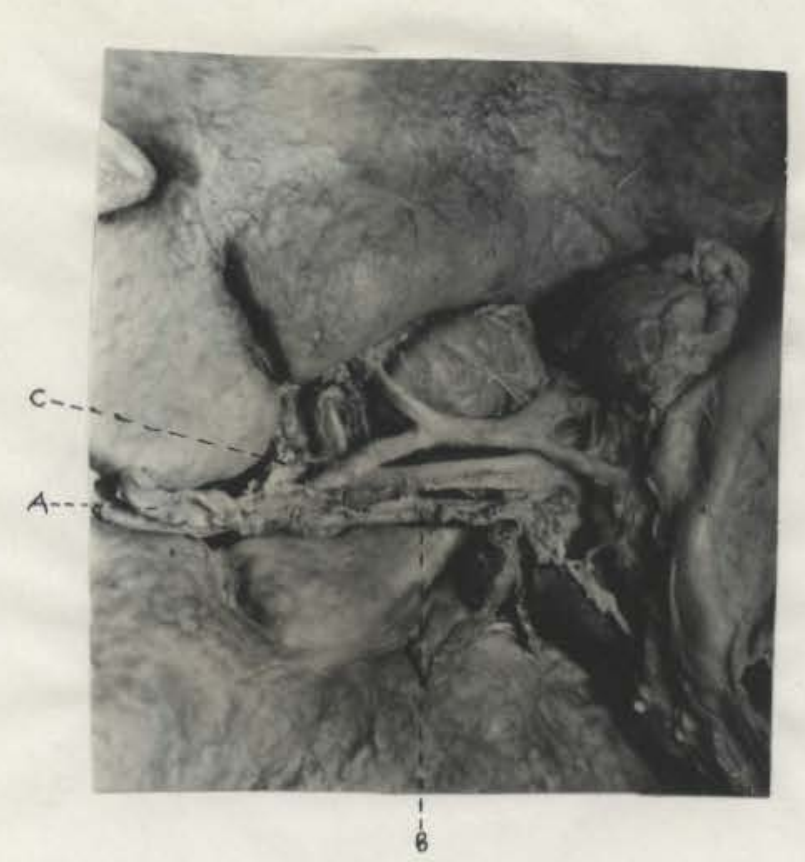

Case L. C. Dissection of extra hepatic ducts. A gall bladder; B - stenosed common duct; C - stenosed hepatic duct.

The gall bladder was located within the right lobe of the liver and was a blind pouch and had no connection with the intra hepatic ducts. The wa.ll of the gall bladder was thick and contracted. The right and left hepatic ducts were found but contained no lumen and the common duct was a strand of fibrous tissue without a duct.

The duodenum and pancreas were normal and the intestinal fecal contents were light in color. There was a tumor in the region of the anterior fontanelle, three centimeters in diameter which appeared to be a 
hemangioma.

The anatomical diagnosis was: congenital malformation of right and left hepatic, cystic, and common ducts, cirrhosis of the liver, splenomegalia, ascites, bile nephrosis of both kidneys, umbilical hernia.

\section{Case III}

M. E., a white child, age 5 months, a referred case, was first seen by Dr. N. F. Hicken, January 15, 1936. Its chief complaint was jaundice since birth. At the age of one month the child was thought to have had a trace of bile in the stools and the liver and spleen were barely palpable. The jaundice seemed to subside somewhat and the stools took on a yellowish tinge during the first and second months, but again became clay colored. After the second month the jaundice progressively increased. At no time during the first four months was there any signs of diarrhea, fatty stools, hemorrhage, pruritis, pain, or temperature. The child was observed on the fifth month to have its spleen extending below the umbilicus, and the liver at the crest of the ilium.

Physical examination on the fifth month showed the child to be markedly jaundiced, and well nourished. 
The abdomen was protruberant and masses were seen in the liver and splenic regions. The Van der Bergh reaction was immediate directly positive, erythrocyte fragility was normal, and the icterus index was sixty, Wassermann negative, and reticulocyte count normal.

A photograph of the child was then taken. It was the impression of the attending purgeon that the correct diagnosis was congenital atresia of the extra hepatic ducts.

As pre-operative preparation the child was given percomorph oil, gtts $\overline{\mathbf{x}}$, TID, calcium lactate, 3 5s TID, a high carbohydrate diet, and a transfusion of two hundred cc of whole blood.

An exploratory celiotomy was done January 18, 1936 under an ether anesthetic. The liver was found to extend $5 \frac{1}{2}$ centimeters below the costal margin, its surface was hard, firm, nodular and was a bluish-green color. Pilot nodes were seen along what was thought to be the cystic duct. No bile was obtained from the aspiration of any duct-like structure. Nothing which resembled the right and left hepatic or common ducts was seen. A biopsy taken of the nodes in the cystic duct region showed them to be lymphadenopathies. Two cc of skiodan was injected into the gall bladder 
region and at the time it was thought that it dissected between the peritoneal reflections along the ventral surface of the liver. X-Ray plates were taken and the abdomen closed.

Post operatively the child developed bronchial pneumonia, was given a transfusion, but became cyanotic and died on the second day.

Permission was given by the child's parents to explore the liver through the operative incision.

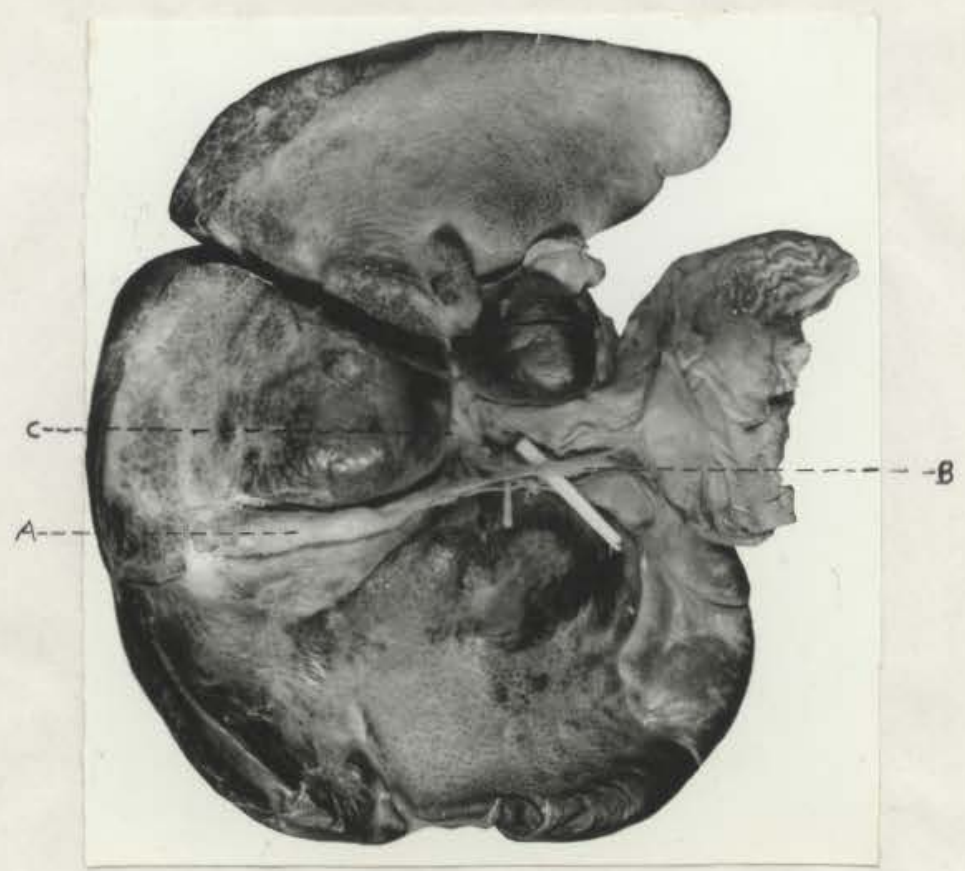

Case M. E. Dissection showing extra hepatic ducts.
A - Ga.ll bladder; B - Common duct; C - Stenosed hepatic duct. 
It was found by thorough exploration, and confirmed by further injection of lipiodine and taking of $x$-ray piotures, that the pancreatic duct was patent and was connected with the common duct and a narrow, elongated gall bladder. The hepatic duct was a solid cord and was not connected to the common duct. The cystic duct was absent. The fibrous remnants of the right and left hepatic ducts were compressed by a fibrous tumor mass $4 \mathrm{~cm}$ in diameter within the liver substance.

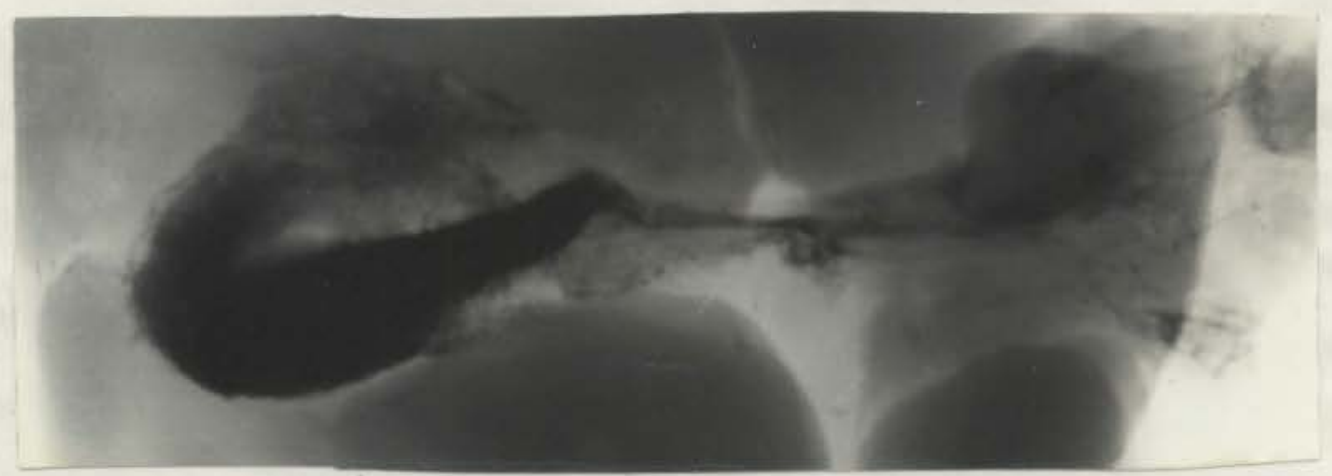

Case M. E. Cholangiogram. Injection of gall bladder shows common duct patent, hepatic duct absent.

\section{Case IV}

B. J., a white female child, age five months, was first seen as a referred case by Dr. R. R. Best, Omaha, on December 12, 1937.

The child had been jaundiced since birth, the urine was dark, and the stools had varied between a 
clay and a light yellow color. No increase in the jaundice was seen between the third and the fourth month.

Other than the child's maternal second cousin who had several babies who were jaundiced a few days following birth, the family history was negative.

At the age of four and one half months the child developed severe pain, the stools became definitely clay colored, and the jaundice deepened. The appetite was good-and a slight weight gain was noticed.

Physical examination at the fifth month showed deep generalized jaundice, splenic and liver enlargement, the latter being two and one-half $\mathrm{cm}$ below the right costal margin.

On admission to the hospital at the fifth month the temperature was normal, the icterus index was one hundred thirty eight, the Van der Bergh reaction was immediately direct and strongly positive, erythrocyte fragility was normal, the blood count showed 4,500,000 red blood cells, 14,800 white cells, 37\% neutrophiles, and $60 \%$ lymphocytes, and the bleeding and clotting time were two minutes each. There were three to five stools per day which were acholic and occasionally showed a trace of blood. 
On the seventh day following admission the child developed an upper respiratory infection and otitis media for which a paracentesis of the left ear was done.

On the second week, following recovery from the ear infection, an exploratory celiotomy was done under novocain-either anesthesia. The abdomen contained several ounces of bile stained fluid. Exploration from the duodenum to porta hepatis showed no definite evidence of ducts, and the gall bladder was absent. A cord of fibrous tissue one $\mathrm{mm} x$ one $\mathrm{cm}$ was seen leading from the right hepatic artery and was believed to be the cystic artery anlage. The abdomen was then closed and the child died six hours post operatively, most likely because of the adoed insult of surgery upon the damaged liver. Exploration of the incision following death confirmed the diagnosis of complete absence of extra hepatic ducts and gall bladder. Also, there was considerable blood in the peritoneal cavity which was probably a factor of the early exodus.

\section{Case V}

H. V., a white male child, age three months, 
entered the pediatrics sexvice of Dr. E. W. Bantin. at the University of Nebraska Hospital June 21, 1938, showing increasing jaundice, intermittant acholic stools and fretfulness since birth.

This child was the third, the others being normal. The delivery was normal and the birth weight was seven and one-half pounds. He was breast fed for the first two months and had a good appetite. On the third week severe bleeding followed a circumcision. On the second month the child developed red spots on the knees and ankles which turned blue, and finally disappeared. At this time also vomiting developed which lasted for two weeks, and a diarrhea, accompanied by red blood in the stools, was noticed and persisted for three days.

As regards to family history, carcinoma was present in the paternal grandfather and aunt. The child's mother and maternal aunt were icteric infants.

Physical examination at the time of admission showed the child to be in a state of good nutrition. The jaundice was marked and generalized, the abdomen was distended, the spleen was palpable, and the liver was down to the umbilicus.

Laboratory studies showed the serology negative, 
the Van der Bergh was direct and immediately positive. The icterus index was sixty, erythrocyte fragility was normal. The platelet count was 94,000 and the reticulocyte count $3.5 \%$. Urine was strongly positive for bile, and the bleeding and clotting time were two and two and one-half minutes respectively. Hemoglobin was fifty percent, the red count three million and the white count eleven thousand.

Surgical consultation was asked and Dr. N. Frederick Hicken responded, making a tentative diagnosis of congenital atresia of the bile ducts.

An exploratory celiotomy was done under ether anesthesia two weeks after admission. The liver was green and had a hard nodular surface. A small gall bladder was found which on aspiration contained no bile. A small common duct was present but no hepatic duct could be found. A firm node proximal to the gall bladder was shown to be chronic lymphadenitis upon biopsy examination.

The child's temperature rose to 106 following operation and he expired thirty six hours later.

The autopsy showed the enlarged liver to extend down to the iliac crest, the spleen to weigh 60 grams (twice the normal) and the small bowel to be moderately 
distended with gas. A few $c c$ of yellowish fluid were seen in the peritoneal cavity.

Both lungs show petechial hemorrhages over their surface, patchy atelectasis through the lower lobes, and marked congestion.

Pressure over the ga.ll bladder forces clear mucus out the amoule of Vater. A small papilla, probably representing the duct of Santovini is seen eight $\mathrm{cm}$. proximal to the ampulla of Vater.

Case H. V. Cholangiogram. Skiodan injected into ampule of Vater at autopsy, showing absence of hepatic duct lumen

Skiodan was injected into the ampule of Vater and gall bladder and $\mathrm{x}$-ray demonstrated the pancreatic radicles to be normal and the common and cystic ducts patent and communicating with the gall bladder which 
appeared normal. Dissection of the hepatic ducts showed there to be solid fibrous cords, five $\mathrm{mm}$. in diameter.

The surface of the liver is deeply bile stained, markedly roughened, and the cut surface shows slight accentuation of markings due to marked pigmentation. Microscopically, much of the liver parenchyma was replaced by fibrous tissue. The entire architecture is much modified, and the liver substance shows marked fatty degeneration. The intra hepatic ducts are dilated, filled with bile, and their epithelium shows extensive proliferation.

A section of fibrous tissue taken from the cystic duct region shows numerous irregularly defined islands of bile duct epithelium which may represent an ineffectual apptempt to produce normal bile ducts.

The anatomical diagnosis was congenital atresia of hepatic portion of bile duct, cirrhosis of the liver, congenital bifurcation of the right kidney pelvis with cloudy swelling of both kidneys, and bronchial pneumonia.

\section{Conclusions}

1. All of the above cases were shown by operation 
or autopsy to be inoperable.

2. Ascites usually occurs from the fourth to sixth month.

3. The use of a fat-free diet and bile salts in infants with congenital atresia of the bile ducts is a prime adjunct in maintaining the optimum nutritional state.

4. Children with congenital atresia of the bile duct past the age of three months tolerate surgical procedures poorly.

5. The use of the cholangiogram at the operating table in cases of congenital atresia of the bile ducts is a noteworthy advance in surgical treatment, as the accuracy of diagnosis is increased, and the resulting trauma is much lessened. 


\section{BIBLIOGRAPHY}

Bibliography List - Alphabetical

1. Altschule - Vitamin Deficiency in Congenital

Atresia of Bile Ducts - Archives of Pathology $20,845-56,1935$

2. Bower, J. 0. - Congenital Absence of the Gall Bladder - Annals of Surgery, 88, 80-90, 1928

3. Cole, W. H. - Congenital Malformations of Bile Ducts and Intestinal Tract in Infants Archives of Surgery, 23, 820-47, 1931

4. Croswell, C. V. - Oongenital Absence of Extra Hepatic Ducts and Gall Bladder - Journal of the Tennessee Medical Association 27, 316-9, 1934

5. Deaver, J. M. B. - Congenital Absence of Extra Hepatic Ducts and Gall Bladder - American Journal of Diseases of Children 46, 356-81, 1933

6. Donovan, E. J. - Congenital Atresia of the Bile Ducts - Annals of Surgery 106, 737-44, 1937

7. Eisendrath, D. N. - Anomalies of Bile Ducts and Blood Vessels - Journal of the American Medical association $71,864-5,1918$ 
8. Gordon, J. K. - Congenital Obliteration of Bile Ducts and Congenital Biliary Cirrhosis of the Liver - Boston Medical and Surgical Journal $187,928-8,1922$

9. Hill, N. H. - Congenital Atresia of the Bile Ducts - Lancet 2, 654-5, 1927

10. Holmes, J. B. - Obliteration of Bile Ducts - American Journal of Diseases of Children 11, 405-29, 1916

11. Howard, C. D., and Wolbach, S. B. - Congenital Obliteration of Bile Ducts - Archives of Internal Medicine 8, 557-73, 1911

12. Kieth, T. S. - Congenital Obliteration of the Bile Ducts - Proceedings of the Royal Society of Medicine 25, 1735-6, 1932

13. Kirshbaum, J. D. - Congenital Absence of Gall Bladder and Extra Hepatic Ducts - American Journal of Diseases of Children 47, 1080-6, 1934

14. Laboe, E. W.--Congenital Absence of the Bile Ducts - Journal of the Indiana Medical Association $27,373-6 ; 1934$

15. Ladd, W. E. - Congenital Atresia and Stenosis of. the Bile Ducts - Journal of the American Medical Association 91, 1082-4, 1928 16. Ladd, W. E. - Congenital Atresia of the Bile Ducts - Annals of Surgery 102, 742-50, 1935 
17. Lavenson, R. S. - Congenital Obliteration of the Ducts with Cirrhosis of the Liver - Journal of Medical Research 18, 61-71, 1908

18. Mason, J. T. - Technic of Cholecystogastrostomy Journal American Medical Association 94, $29-31,1930$

19. Milne, L. S. - Congenital Atresia of the Bile Passages - Quarterly Journal of Medicine 5, $409-18,1911$

20. Montgomery A. H. - Oongenital Obstruction of the Bile Ducts - Surgical Clinics of North America, 16, 93-100, 1936

21. McClendon, S. J., and Graham, H. K. - Congenital Atresia of the Hepatic Duct - Archives of Pediatrics $48,791-4,1931$

22. Parsons, L. G., and Herkman, E. M. - Biliary Cirrhosis - American Journal of Diseases of Children 31, 459-68, 1926

23. Rosenberg and Judd - Congenital Atresia of the Bile Ducts - Archives of Surgery 18, 2339, 1929 24. Rolleston, H. D. and Hayne, I. B. - Congenital Obliteration of the Extra Hepatic Ducts British Medical Journal 1, 758-72, 1901

25. Scriven, J. B. - Congenital Absence of Hepatic and Oommon Ducts - Oanadian Medical Association Journa.1 27, 517-8, 1932 
26. Sweet, L. K. - Congenital Malformations of the Bile Ducts - Journal of Pediatrics 1, 496-9 1932

27. Watkins, A. J., and Wright, G. P. - Congenital Atresia of the Bile Ducts - Lancet 1, 1066-8 1933

28. Wyard, 8. - A Case of Congenital Atresia of the Bile Ducts - Lancet 2, 495, 1914

\section{ACKNOWLEDGEMENT}

The author wishes to thank Doctors J. A. Henske, R. R. Best, C. P. Baker, J. P. Tollman, and Miss Rose Reynolds for their cooperation in the preparation of the case studies. He is greatly indebted to $\mathrm{Dr} . \mathrm{N}$. Frederick Hicken for many helpful suggestions and criticisms. 